\title{
Development of possibilistic statistics and its application to quantify uncertainty of subsurface solute transport model
}

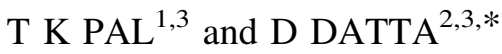 \\ ${ }^{1}$ Technology Development Division, Bhabha Atomic Research Centre (BARC), Mumbai 400085, India \\ ${ }^{2}$ Radiological Physics and Advisory Division, Bhabha Atomic Research Centre (BARC), Mumbai 400085, India \\ ${ }^{3}$ Homi Bhabha National Institute, Mumbai 400094, India \\ e-mail: ddatta@barc.gov.in
}

MS received 7 March 2018; revised 25 October 2018; accepted 31 October 2018; published online 1 February 2019

\begin{abstract}
Imprecise information on any system is addressed by possibility theory wherein the system is modeled as a fuzzy set. Alpha level representation of a fuzzy set in the form of an interval defines the possibility theory. Uncertainty of any model in this context is quantified as mean value \pm standard deviation of a possibilistic (imprecise) parameter. This paper presents the possibilistic statistical techniques to estimate the mean and standard deviation of a possibilistic parameter of subsurface solute transport model. The solute transport model parameters, such as groundwater velocity, solute dispersion coefficient, etc., are sparse and imprecise in nature. Such parameters are characterized by the possibility distribution. In this paper, analytical expression of solute transport model is used to estimate the mean value and standard deviation of possibilistic spatial and temporal concentration of solute.
\end{abstract}

Keywords. Possibility theory; fuzzy logic; uncertainty analysis; solute transport.

\section{Introduction}

Subsurface solute transport model, which is mathematically represented by advection-dispersion equation (ADE), is widely used in the field of nuclear science and technology to estimate spatio-temporal profile of the radionuclides disposed of in a geological repository. The geological media, which is composed of rock, soil, clay, etc., is highly heterogeneous in nature. Due to this heterogeneous structure, uncertainty in the predicted solute concentration will be obvious if we consider associated properties of the material such as porosity, material density and physicochemical properties such as groundwater velocity, dispersion coefficient, and distribution coefficient as crisp parameters. These uncertain model parameters propagate uncertainty through the solute transport model, and therefore uncertainty modeling of solute transport model is very important from the point of safety of radioactive waste disposal module [1]. Uncertainty of a model due to its parameters can be of two types: aleatory and epistemic uncertainty [2, 3]. In the aleatory uncertainty, model parameters are random in nature, whereas in epistemic uncertainty model parameters are imprecise in nature due to insufficiency in the experimentally measured data volume, lack of information and/or due to use of linguistic variable such as experts opinion [3].

*For correspondence
Classical statistics deals with the random variable characterized by a specific probability distribution. For example, a continuous random variable is characterized by its probability density function such as normal, exponential, lognormal, etc. [4]. Randomness of a variable is possible to identify for a large number of samples. However, in practice, large sample size $(>10000)$ of any physical parameter (assuming it is random) is impossible to generate. This inhibits the user to specify the possible values of the targets or parameters of any experiments. This is always true for an environmental model such as subsurface solute transport. In fact, subsurface solute transport model consists of two such imprecise parameters, viz. flow velocity and diffusion coefficient. Fuzzy set theory [5] is well suited to represent these imprecise parameters. Membership function of solute concentration is computed using fuzzy vertex theory. Researchers have carried out fuzzy set based uncertainty modeling of solute transport using analytical as well as numerical techniques such as finite difference method [6], differential quadrature method [7], lattice Boltzmann method [8], etc. In the fuzzy set based uncertainty modeling uncertainty of outcome of the model is expressed in terms of $\alpha$-cuts, which is not a good form of representation of uncertainty for decision makers. A possibility distribution is numerically represented as membership function of a possibilistic variable. This is a fundamental concept coined by Zadeh [9] in the possibility theory. Concept of the possibilistic distribution is utilized to estimate the mean and 
standard deviation in the possibilistic space [10]. Possibilistic mean can be also interpreted as an interval-valued expectation of a fuzzy number [11]. Dubois and Prade used the concept of a constant random set to derive the expectation value of a fuzzy number [11]. Carlsson and Fuller expressed the interval valued expectation of a fuzzy number as lower and upper possibilistic mean [12]. According to their work, crisp possibilistic mean can be computed by average of lower and upper possibilistic mean.

In this paper, the parameters of solute transport model such as groundwater velocity and dispersion coefficient are treated as possibilistic parameter [10] and their representation is specified in terms of a fuzzy set $[13,14]$. Alpha cut representation of these fuzzy sets provide the information on their possible values [15]. In the domain of nuclear waste disposal in geological repository possible measurements are always expressed with their nominal values and one/two sigma level scatter. In this context, it is interpreted as the measured value has a fuzziness due to small sample size ( $\sim 5$ maximum) which is further approximately reasoned as 'around nominal value'. Since triangular fuzzy membership function is signified in the domain of approximate reasoning 'around the mean or nominal value', the fuzziness of the uncertain variable used in this paper is measured in terms of triangular fuzzy number. This follows strictly for the domain of nuclear waste deposal scenario.

This paper is organized in the following way: In section 2, preliminary statistics of a possibilistic variable is first reviewed with numerical examples. In section 3, the same statistics is applied to the possibility distribution of solute concentration obtained from analytical solution of 1D subsurface solute transport model. Results and discussions are given in section 4. Finally, conclusions are drawn in section 5 .

\section{Preliminary of possibilistic statistics}

This section addresses the fundamental concepts of fuzzy variable with its associated possibility distribution. Basically, quantification of uncertainty of an imprecise system is carried out using the possibility distribution as we do the estimation of variability of a random system using corresponding probability distribution. Details about fuzzy set and possibility theory can be found elsewhere in $[10,13-15]$.

\subsection{Definition: fuzzy set and alpha-cut}

A fuzzy set is defined as a paired numbers as $A=\{x, \mu(x) \mid$ $x \in R, \mu(x) \in[0,1]\}$, where $\mu(x)$ represents the membership grades of the crisp value, $\mathrm{x}$. The normalization of a fuzzy set $\mathrm{A}$ is generally defined as that fuzzy set whose maximum membership value is 1 . Further, as per [13-15], a fuzzy set is said to be convex under the constraint condition of the inequality written as, $\mu_{\mathrm{A}}(\mathrm{c}) \geq \min \left(\mu_{\mathrm{A}}(\mathrm{a}), \mu_{\mathrm{A}}(\mathrm{b})\right)$. The definition $\alpha$-cut of a fuzzy set is found elsewhere in $[14,15]$.

\subsection{Definition: fuzzy number}

Fuzzy numbers are special cases of fuzzy sets with a normal, fuzzy convex and continuous membership function of bounded support. Generally two types of fuzzy membership functions (triangular and trapezoidal) are used to illustrate uncertainties associated with the model parameters. Mathematical formulation of a triangular fuzzy number is governed by Eq. (1). The schematic view of a triangular membership function is shown in figure 1 .

$$
\mu(x)=\alpha= \begin{cases}\frac{x_{L}-a}{b-a}, & a \leq x_{L} \leq b \\ \frac{c-x_{R}}{c-b}, & b \leq x_{R} \leq c \\ 0, & \text { otherwise }\end{cases}
$$

The $\alpha$-cut of a fuzzy number is an interval defined for a specific value of membership function and is mathematically defied as

$$
\begin{aligned}
{[\mathrm{A}]_{\alpha} } & =\left[\mathrm{x}_{\mathrm{L}}^{\alpha}, \mathrm{x}_{\mathrm{U}}^{\alpha}\right] \\
& =[\mathrm{a}+(\mathrm{b}-\mathrm{a}) \alpha, \mathrm{c}-(\mathrm{c}-\mathrm{b}) \boldsymbol{\alpha}]
\end{aligned}
$$

\subsection{Definition: possibility distribution}

According to Zadeh [9], the possibility distribution of $\mathrm{X}$, $\pi_{X}$, is the membership function of that fuzzy set. The state can be written as

$$
\forall x \in U, \quad \pi_{X}(x)=\mu_{A}(x)
$$

where, $\mathrm{U}$ is the universe of discourse on which $\mathrm{X}$ ranges. Possibility distribution is basically a mapping of the element of a fuzzy set to the order scale $[0,1]$.

$$
\pi_{A}: x \rightarrow[0,1]
$$

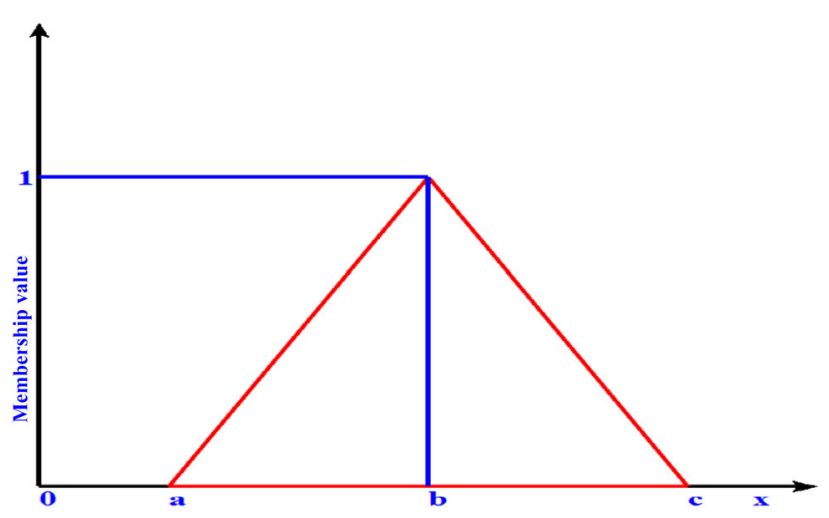

Figure 1. Triangular fuzzy membership function. 


\subsection{Definition: interval valued possibilistic mean}

Lower possibilistic mean (lower limit of interval) of a fuzzy number, $\left\{\mathrm{x}, \mu_{\mathrm{A}}(\mathrm{x})\right\}$, is defined as the possibility weighted average of the lower part of the $\alpha$-cut and can be written

$$
\begin{aligned}
\mathrm{M}_{\mathrm{L}}(\mathrm{A}) & =\frac{\int_{0}^{1} \operatorname{Pos}\left[\mathrm{a} \leq \mathrm{x}_{\mathrm{L}}^{\alpha}\right] \times \min \left[\mathrm{A}_{\alpha}\right] \mathrm{d} \alpha}{\int_{0}^{1} \operatorname{Pos}\left[\mathrm{a} \leq \mathrm{x}_{\mathrm{L}}^{\alpha}\right] \mathrm{d} \alpha} \\
& =\frac{\int_{0}^{1} \alpha \mathrm{x}_{\mathrm{L}}^{\alpha} \mathrm{d} \alpha}{\int_{0}^{1} \alpha \mathrm{d} \alpha} \\
& =2 \int_{0}^{1} \alpha \mathrm{x}_{\mathrm{L}}^{\alpha} \mathrm{d} \alpha
\end{aligned}
$$

where the possibility of $A \leq \mathrm{x}_{\mathrm{L}}^{\alpha}$ is denoted as $\operatorname{Pos}\left[\mathrm{a} \leq \mathrm{x}_{\mathrm{L}}^{\alpha}\right]=\alpha$. In the similar way upper possibilistic mean (upper limit of the interval) is the possibility weighted average of the upper part of the $\alpha$-cut

$$
\begin{aligned}
\mathrm{M}_{\mathrm{U}}(\mathrm{A}) & =\frac{\int_{0}^{1} \operatorname{Pos}\left[\mathrm{a} \geq \mathrm{x}_{\mathrm{R}}^{\alpha}\right] \times \max \left[\mathrm{A}_{\alpha}\right] \mathrm{d} \alpha}{\int_{0}^{1} \operatorname{Pos}\left[\mathrm{a} \geq \mathrm{x}_{\mathrm{R}}^{\alpha}\right] \mathrm{d} \alpha} \\
& =\frac{\int_{0}^{1} \alpha \mathrm{x}_{\mathrm{U}}^{\alpha} \mathrm{d} \alpha}{\int_{0}^{1} \alpha \mathrm{d} \alpha}=2 \int_{0}^{1} \alpha \mathrm{x}_{\mathrm{U}}^{\alpha} \mathrm{d} \alpha
\end{aligned}
$$

where the possibility of $A \geq \mathrm{x}_{\mathrm{L}}^{\alpha}$ is denoted as $\operatorname{Pos}\left[\mathrm{a} \geq \mathrm{x}_{\mathrm{R}}^{\alpha}\right]=$ $\alpha$ and $\mathrm{M}_{\mathrm{L}}(\mathrm{A})$ and $\mathrm{M}_{\mathrm{U}}(\mathrm{A})$ are the lower and upper possibilistic mean values of $A$. On the basis of the lower and upper limit of the possibilistic mean, we can define intervalvalued possibilistic mean of $A$ as

$$
\mathrm{M}(\mathrm{A})=\left[\mathrm{M}_{\mathrm{L}}(\mathrm{A}), \mathrm{M}_{\mathrm{U}}(\mathrm{A})\right]
$$

\subsection{Definition: crisp possibilistic mean}

Possibilistic mean value of fuzzy variable A (crisp in nature) is the arithmetic mean of its lower and upper possibilistic mean values, i.e.,

$$
\begin{aligned}
\bar{M}(\mathrm{~A}) & =\frac{\mathrm{M}_{\mathrm{L}}(\mathrm{A})+\mathrm{M}_{\mathrm{U}}(\mathrm{A})}{2} \\
& =\int_{0}^{1} \alpha \mathrm{x}_{\mathrm{L}}^{\alpha} \mathrm{d} \alpha+\int_{0}^{1} \alpha \mathrm{x}_{\mathrm{U}}^{\alpha} \mathrm{d} \alpha \\
& =\int_{0}^{1} \alpha\left(\mathrm{x}_{\mathrm{L}}^{\alpha}+\mathrm{x}_{\mathrm{U}}^{\alpha}\right) \mathrm{d} \alpha
\end{aligned}
$$

\subsection{Definition: possibilistic variance}

Possibilistic variance of $\mathrm{A}$ is defined as the second order moment of the endpoints of $\alpha$-cut with respect to the arithmetic mean of the endpoints of that $\alpha$-cut

$$
\begin{aligned}
\operatorname{Var}(\mathrm{A})= & 2 \int_{0}^{1} \alpha\left[\frac{\mathrm{x}_{\mathrm{L}}^{\alpha}+\mathrm{x}_{\mathrm{U}}^{\alpha}}{2}-\mathrm{x}_{\mathrm{L}}^{\alpha}\right]^{2} \mathrm{~d} \alpha \\
& +2 \int_{0}^{1} \alpha\left[\frac{\mathrm{x}_{\mathrm{L}}^{\alpha}+\mathrm{x}_{\mathrm{U}}^{\alpha}}{2}-\mathrm{x}_{\mathrm{U}}^{\alpha}\right]^{2} \mathrm{~d} \alpha
\end{aligned}
$$

Simplifying the above equation we get

$$
\begin{aligned}
\operatorname{Var}(\mathrm{A})= & \frac{1}{2} \int_{0}^{1} \alpha\left[\mathrm{x}_{\mathrm{U}}^{\alpha}-\mathrm{x}_{\mathrm{L}}^{\alpha}\right]^{2} \mathrm{~d} \alpha \\
& +\frac{1}{2} \int_{0}^{1} \alpha\left[\mathrm{x}_{\mathrm{U}}^{\alpha}-\mathrm{x}_{\mathrm{L}}^{\alpha}\right]^{2} \mathrm{~d} \alpha \\
= & \int_{0}^{1} \alpha\left[\mathrm{x}_{\mathrm{U}}^{\alpha}-\mathrm{x}_{\mathrm{L}}^{\alpha}\right]^{2} \mathrm{~d} \alpha
\end{aligned}
$$

The possibilistic standard deviation of A is defined by

$$
\sigma(\mathrm{A})=\sqrt{\operatorname{Var}(\mathrm{A})}
$$

\subsection{Definition: possibilistic skewness}

Possibilistic skewness (PS) is the ratio between third order possibilistic moment of the endpoints of $\alpha$-cut with respect to the arithmetic mean of the endpoints of that $\alpha$-cut and cube of possibilistic standard deviation. Third order possibilistic moment is defined as

$$
\begin{aligned}
\mathrm{M}_{3}(\mathrm{~A})= & 2 \int_{0}^{1} \alpha\left[\frac{\mathrm{x}_{\mathrm{L}}^{\alpha}+\mathrm{x}_{\mathrm{U}}^{\alpha}}{2}-\mathrm{x}_{\mathrm{L}}^{\alpha}\right]^{3} \mathrm{~d} \alpha \\
& +2 \int_{0}^{1} \alpha\left[\frac{\mathrm{x}_{\mathrm{L}}^{\alpha}+\mathrm{x}_{\mathrm{U}}^{\alpha}}{2}-\mathrm{x}_{\mathrm{U}}^{\alpha}\right]^{3} \mathrm{~d} \alpha \\
= & \frac{1}{4} \int_{0}^{1} \alpha\left[\mathrm{x}_{\mathrm{U}}^{\alpha}-\mathrm{x}_{\mathrm{L}}^{\alpha}\right]^{3} \mathrm{~d} \alpha \\
& +\frac{1}{4} \int_{0}^{1} \alpha\left[\mathrm{x}_{\mathrm{L}}^{\alpha}-\mathrm{x}_{\mathrm{U}}^{\alpha}\right]^{3} \mathrm{~d} \alpha \\
= & \frac{1}{4} \int_{0}^{1} \alpha\left[\mathrm{x}_{\mathrm{U}}^{\alpha}-\mathrm{x}_{\mathrm{L}}^{\alpha}\right]^{3} \mathrm{~d} \alpha \\
& -\frac{1}{4} \int_{0}^{1} \alpha\left[\mathrm{x}_{\mathrm{U}}^{\alpha}-\mathrm{x}_{\mathrm{L}}^{\alpha}\right]^{3} \mathrm{~d} \alpha=0
\end{aligned}
$$

Therefore, 


$$
\mathrm{PS}=\frac{\mathrm{M}_{3}(\mathrm{~A})}{\sigma(\mathrm{A})^{3}}=0
$$

\subsection{Definition: possibilistic kurtosis}

Possibilistic kurtosis of a possibility distribution is the ratio between the fourth order possibilistic moment about crisp possibilistic mean and fourth power of possibilistic standard deviation. Forth order possibilistic moment is given as

$$
\begin{aligned}
\mathrm{M}_{4}(\mathrm{~A})= & 2 \int_{0}^{1} \alpha\left[\frac{\mathrm{x}_{\mathrm{L}}^{\alpha}+\mathrm{x}_{\mathrm{U}}^{\alpha}}{2}-\mathrm{x}_{\mathrm{L}}^{\alpha}\right]^{4} \mathrm{~d} \alpha \\
& +2 \int_{0}^{1} \alpha\left[\frac{\mathrm{x}_{\mathrm{L}}^{\alpha}+\mathrm{x}_{\mathrm{U}}^{\alpha}}{2}-\mathrm{x}_{\mathrm{U}}^{\alpha}\right]^{4} \mathrm{~d} \alpha \\
= & \frac{1}{8} \int_{0}^{1} \alpha\left[\mathrm{x}_{\mathrm{U}}^{\alpha}-\mathrm{x}_{\mathrm{L}}^{\alpha}\right]^{4} \mathrm{~d} \alpha \\
& +\frac{1}{8} \int_{0}^{1} \alpha\left[\mathrm{x}_{\mathrm{L}}^{\alpha}-\mathrm{x}_{\mathrm{U}}^{\alpha}\right]^{4} \mathrm{~d} \alpha \\
= & \frac{1}{4} \int_{0}^{1} \alpha\left[\mathrm{x}_{\mathrm{U}}^{\alpha}-\mathrm{x}_{\mathrm{L}}^{\alpha}\right]^{4} \mathrm{~d} \alpha
\end{aligned}
$$

Therefore, possibilistic kurtosis can be written as

$$
\operatorname{Kur}(\mathrm{A})=\frac{\mathrm{M}_{4}(\mathrm{~A})}{\sigma(\mathrm{A})^{4}}
$$

Substituting the value of possibilistic standard deviation in the above equation we get

\subsection{Numerical example}

$$
\operatorname{Kur}(\mathrm{A})=\frac{1}{4} \frac{\int_{0}^{1} \alpha\left[\mathrm{x}_{\mathrm{U}}^{\alpha}-\mathrm{x}_{\mathrm{L}}^{\alpha}\right]^{4} \mathrm{~d} \alpha}{\left[\int_{0}^{1} \alpha\left[\mathrm{x}_{\mathrm{U}}^{\alpha}-\mathrm{x}_{\mathrm{L}}^{\alpha}\right]^{2} \mathrm{~d} \alpha\right]^{2}}
$$

Suppose we have a triangular fuzzy number $\mathrm{A}(\mathrm{a}, \mathrm{b}, \mathrm{c})$, where $b$ is centre value, $a$ is the left width and $c$ is the right width. Alpha representation of $\mathrm{A}$ is defined by Eq. (2). Lower and upper possibilistic mean can be written as

$$
\begin{aligned}
\mathrm{M}_{\mathrm{L}}(\mathrm{A}) & =\frac{\int_{0}^{1} \alpha \mathrm{x}_{\mathrm{L}}^{\alpha} \mathrm{d} \alpha}{\int_{0}^{1} \alpha \mathrm{d} \alpha} \\
& =\frac{\int_{0}^{1} \alpha[\mathrm{a}+(\mathrm{b}-\mathrm{a}) \alpha] \mathrm{d} \alpha}{\int_{0}^{1} \alpha \mathrm{d} \alpha} \\
& =\frac{\left[\mathrm{a} \frac{\alpha^{2}}{2}+(\mathrm{b}-\mathrm{a}) \frac{\alpha^{3}}{3}\right]_{0}^{1}}{\left[\frac{\alpha^{2}}{2}\right]_{0}^{1}}
\end{aligned}
$$

$$
\begin{aligned}
& =2\left[\frac{\mathrm{a}}{2}+\frac{\mathrm{b}-\mathrm{a}}{3}\right]=\frac{\mathrm{a}+2 \mathrm{~b}}{3} \mathrm{M}_{\mathrm{U}}(\mathrm{A})=\frac{\int_{0}^{1} \alpha \mathrm{x}_{\mathrm{U}}^{\alpha} \mathrm{d} \alpha}{\int_{0}^{1} \alpha \mathrm{d} \alpha} \\
& =\frac{\int_{0}^{1} \alpha[\mathrm{c}-(\mathrm{c}-\mathrm{b}) \alpha] \mathrm{d} \alpha}{\int_{0}^{1} \alpha \mathrm{d} \alpha}=\frac{\left[\mathrm{c} \frac{\alpha^{2}}{2}-(\mathrm{c}-\mathrm{b}) \frac{\alpha^{3}}{3}\right]_{0}^{1}}{\left[\frac{\alpha^{2}}{2}\right]_{0}^{1}} \\
& =2\left[\frac{\mathrm{c}}{2}-\frac{\mathrm{c}-\mathrm{b}}{3}\right]=\frac{\mathrm{c}+2 \mathrm{~b}}{3}
\end{aligned}
$$

Interval-valued possibilistic mean as given in Eq. (7) can be written as

$$
\mathbf{M}^{*}(\mathrm{~A})=\left[\frac{\mathrm{a}+2 \mathrm{~b}}{3}, \frac{\mathrm{c}+2 \mathrm{~b}}{3}\right]
$$

Crisp possibilistic mean as given in Eq. (8) can be written as

$$
\bar{M}(A)=\frac{\frac{a+2 b}{3}+\frac{c+2 b}{3}}{2}=\frac{a+c+4 b}{6}
$$

Possibilistic variance of A as given in Eq. (10) can be written as

$$
\begin{aligned}
\operatorname{Var}(\mathrm{A}) & =\int_{0}^{1} \alpha[\mathrm{c}-(\mathrm{c}-\mathrm{b}) \alpha-\mathrm{a}-(\mathrm{b}-\mathrm{a}) \alpha]^{2} \mathrm{~d} \alpha \\
& =\int_{0}^{1} \alpha[\mathrm{c}(1-\alpha)-\mathrm{a}(1-\alpha)]^{2} \mathrm{~d} \alpha \\
& =(\mathrm{c}-\mathrm{a})^{2} \int_{0}^{1} \alpha(1-\alpha)^{2} \mathrm{~d} \alpha \\
& =(\mathrm{c}-\mathrm{a})^{2}\left(\frac{1}{2}-\frac{2}{3}+\frac{1}{4}\right)=\frac{(\mathrm{c}-\mathrm{a})^{2}}{12}
\end{aligned}
$$

Possibilistic standard deviation as given in Eq. (11) can be written as

$$
\sigma(A)=\sqrt{\frac{(c-a)^{2}}{12}}=\frac{c-a}{2 \sqrt{3}}
$$

Forth order possibilistic moment as given in Eq. (14) can be written as

$$
\begin{aligned}
\mathrm{M}_{4}(\mathrm{~A}) & =\frac{1}{4} \int_{0}^{1} \alpha[\mathrm{c}-(\mathrm{c}-\mathrm{b}) \alpha-\mathrm{a}-(\mathrm{b}-\mathrm{a}) \alpha]^{4} \mathrm{~d} \alpha \\
& =\frac{1}{4}(\mathrm{c}-\mathrm{a})^{4} \int_{0}^{1} \alpha(1-\alpha)^{4} \mathrm{~d} \alpha \\
& =\frac{1}{4}(\mathrm{c}-\mathrm{a})^{4} \int_{0}^{1} \alpha\left(1-4 \alpha+6 \alpha^{2}-4 \alpha^{3}+\alpha^{4}\right) \mathrm{d} \alpha \\
& =\frac{1}{4}(\mathrm{c}-\mathrm{a})^{4}\left(\frac{1}{2}-\frac{4}{3}+\frac{6}{4}-\frac{4}{5}+\frac{1}{6}\right) \\
& =\frac{(\mathrm{c}-\mathrm{a})^{4}}{120}
\end{aligned}
$$


Therefore, kurtosis of A as given in Eq. (15) can be written as

$$
\operatorname{Kur}(A)=\frac{(c-a)^{4}}{120} \frac{144}{(c-a)^{4}}=\frac{6}{5}
$$

\section{Case study}

The test problem considered for assessing the uncertainty analysis addresses transport of chemical species with constant source concentration in a saturated aquifer [16-18]. The aquifer is assumed to have infinite length. The governing mathematical equation of this process is 1D ADE. The model calculates spatial and temporal profile of solute. The model parameters measured are two in number, viz. (a) flow velocity (u m/day) and (b) longitudinal dispersivity $\left(\varepsilon_{\mathrm{L}} \mathrm{m}\right)$. The parameters associated with the present model are taken as fuzzy due to their imprecise measurement. Both the fuzzy parameters are represented here as triangular fuzzy number. The governing $1 \mathrm{D}$ ADE is written as

$$
\frac{\partial C}{\partial t}=D_{L} \frac{\partial^{2} C}{\partial x^{2}}-u \frac{\partial C}{\partial x}
$$

where the symbols have usual significances. Longitudinal dispersion coefficient is written mathematically as $D_{L}=\varepsilon_{L} u$. Eq. (16) is subjected to the following initial and boundary conditions:

$$
\begin{gathered}
C(\text { inf }, t)=0 \text { for } \mathrm{t} \geq 0 \\
\mathrm{C}(0, \mathrm{t})=\mathrm{C}_{0} \\
\mathrm{C}(\mathrm{x}, 0)=0
\end{gathered}
$$

where $\mathrm{C}_{0}$ is contaminant source concentration. The model equation (12) with initial and boundary conditions (17)-(19) has analytical solution of the form [6]

$$
\mathrm{C}(\mathrm{x}, \mathrm{t})=\frac{\mathrm{C}_{0}}{2}\left(\operatorname{erfc}\left[\frac{\mathrm{x}-\mathrm{ut}}{\sqrt{4 \mathrm{D}_{\mathrm{L}} \mathrm{t}}}\right]+\exp \left(\frac{\mathrm{ux}}{\mathrm{D}_{\mathrm{L}}}\right) \operatorname{erfc}\left[\frac{\mathrm{x}+\mathrm{ut}}{\sqrt{4 \mathrm{D}_{\mathrm{L}} \mathrm{t}}}\right]\right)
$$

where erfc(y) represents the complementary error function, which in terms of error function can be written as 1-erf(y). The error function has the form

$$
\operatorname{erfc}(y)=\frac{2}{\sqrt{\pi}} \int_{0}^{\mathrm{y}} \mathrm{e}^{-\mathrm{t}^{2}} \mathrm{dt}
$$

The analytical solution of solute concentration as given in Eq. (20) is utilized to calculate solute concentration at various $\alpha$-levels. The fuzzified form of the model solution (20) can be written as

$$
\mathrm{C}_{\alpha}(\mathrm{x}, \mathrm{t})=\frac{\mathrm{C}_{0}}{2}\left(\operatorname{erfc}\left[\frac{\mathrm{x}-\mathrm{u}_{\alpha} \mathrm{t}}{\sqrt{4 \mathrm{D}_{\mathrm{L} \alpha} \mathrm{t}}}\right]+\exp \left(\frac{\mathrm{u}_{\alpha} \mathrm{x}}{\mathrm{D}_{\mathrm{L} \alpha}}\right) \operatorname{erfc}\left[\frac{\mathrm{x}+\mathrm{u}_{\alpha} \mathrm{t}}{\sqrt{4 \mathrm{D}_{\mathrm{L} \alpha} \mathrm{t}}}\right]\right)
$$

Here $\mathrm{u}_{\alpha}$ is the $\alpha$-cut value of groundwater velocity, $\mathrm{D}_{\mathrm{L} \alpha}=\mathrm{u}_{\alpha} \varepsilon_{\mathrm{L} \alpha}$ is the $\alpha$-cut value of longitudinal dispersion coefficient, and $\varepsilon_{\mathrm{L} \alpha}$ represent $\alpha$-cut value of longitudinal dispersion coefficient. The above equation is solved for various $\alpha$-cut values ranging from 0 to 1 . In the simulation, fuzzy vertex method [19] is used to calculate solute concentration using Eq. (22).

\section{Results and discussions}

For estimation of various possibilistic parameters discussed in this paper, we need to estimate possibility distribution of solute concentration, which is nothing but the membership function of solute concentration. The imprecise parameters of the solute transport model are considered as triangular fuzzy variables. The lower, upper and most probable values of the input parameters are taken from [6] as benchmark. The values of input fuzzy parameters are shown in table 1.

Using Eq. (22) time and space dependent solute concentrations are calculated at a specified $\alpha$-cut (0.5). In order to construct the membership function of solute concentration, the simulation is repeated for other $\alpha$ levels such as $0,0.1,0.2,0.3,0.4,0.6,0.7,0.8,0.9$, and 1 . In our study we have taken two sets of computation. In the first set, membership function of solute concentration is computed at a time, $\mathrm{t}=400$ days at different downstream distances ranged from $0 \mathrm{~m}$ to $2000 \mathrm{~m}$. Results of the simulation in the form of solute concentration band comprising of lower, upper and most probable values at $0.5 \alpha$-cut are shown in figure 2 . The membership functions of solute concentration at a fixed time, $\mathrm{t}=400$ days at various locations ranging from $100 \mathrm{~m}$ to $1500 \mathrm{~m}$ at an interval of $100 \mathrm{~m}$ are evaluated and these membership functions are treated as possibilistic distributions of solute concentration. The possibility distributions at three spatial

Table 1. Values of input parameters.

\begin{tabular}{lccc}
\hline Parameters & $\begin{array}{c}\text { Lower } \\
\text { bound }\end{array}$ & $\begin{array}{c}\text { Most likely } \\
\text { value }\end{array}$ & $\begin{array}{c}\text { Upper } \\
\text { bound }\end{array}$ \\
\hline $\begin{array}{l}\text { Ground water velocity } \\
\text { (m/day) }\end{array}$ & 1.8 & 2.4 & 3.1 \\
$\begin{array}{l}\text { Longitudinal } \\
\text { dispersivity (m) }\end{array}$ & 9.2 & 15.3 & 19.8 \\
\hline
\end{tabular}




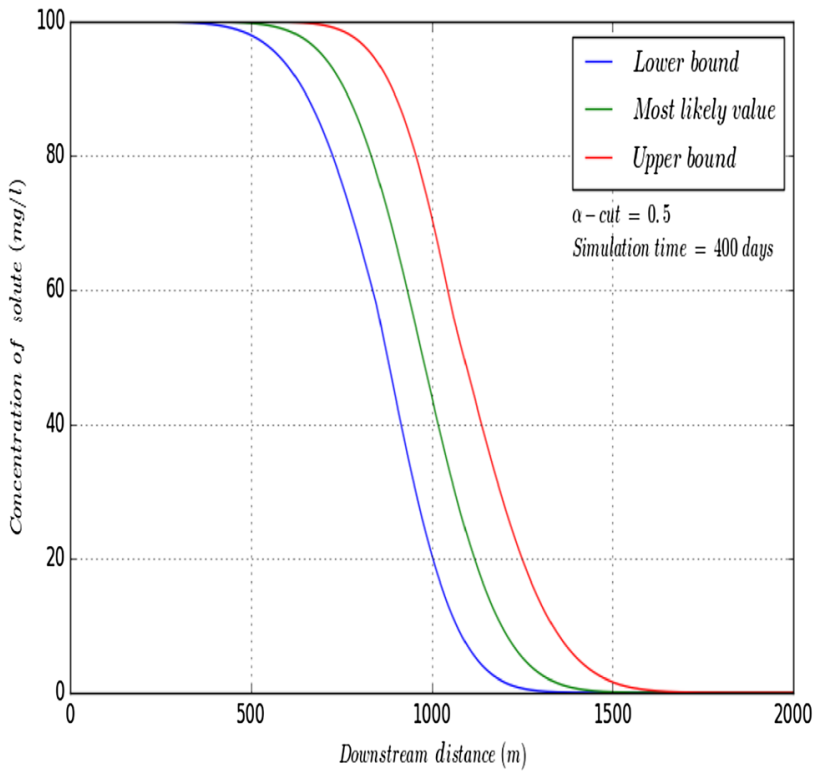

Figure 2. Lower, upper bounds and mostprobable values of solute after 400 days.

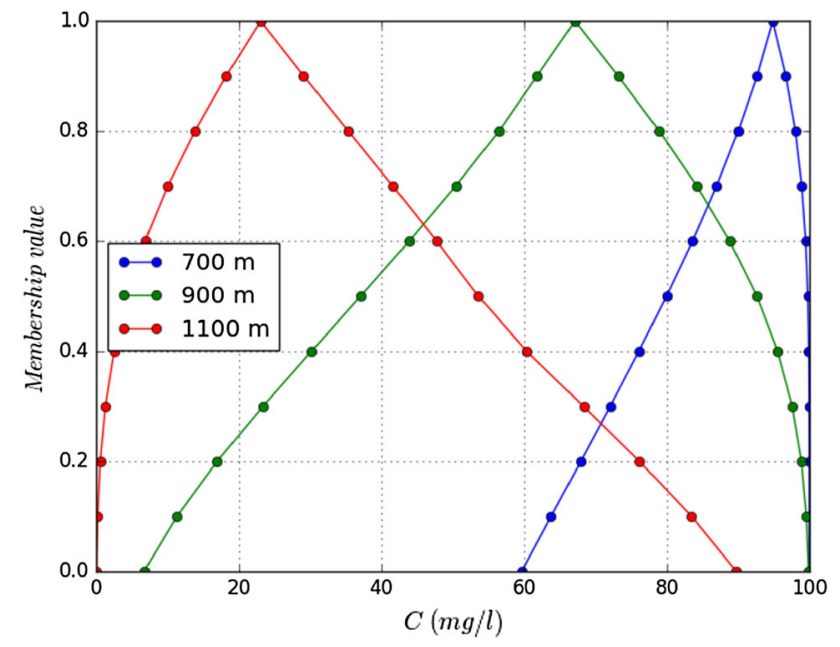

Figure 3. Possibility distribution of solute concentration at downstream distances: $700 \mathrm{~m}, 900 \mathrm{~m}$ and $1100 \mathrm{~m}$ at time, $\mathrm{t}=$ 400 days.

locations, $x=700 \mathrm{~m}, 900 \mathrm{~m}$, and $1100 \mathrm{~m}$ are shown graphically in figure 3 .

The possibilistic parameters discussed in section 2 are calculated from the possibility distribution of solute concentration. The possibilistic parameters calculated at $\mathrm{x}=$ $940 \mathrm{~m}$ and at $\mathrm{t}=400$ days are shown in table 2 . Table 3 represents the possibilistic parameters at various downstream distances.

The spatial variation of the possibilistic coefficient of variation of solute concentration is as shown in figure 4 . It can be observed from the figure 4 that possibilistic
Table 2. Solute concentration at various $\alpha$-cut labels.

\begin{tabular}{|c|c|c|}
\hline \multirow[b]{2}{*}{ Membership value } & \multicolumn{2}{|c|}{$\begin{array}{l}\text { Solute concentration (mg/ } \\
\text { 1) at } 940 \mathrm{~m} \text { downstream } \\
\text { distance after simulation } \\
\text { time } 400 \text { days }\end{array}$} \\
\hline & $\begin{array}{l}\text { Lower } \\
\text { bound }\end{array}$ & $\begin{array}{l}\text { Upper } \\
\text { bound }\end{array}$ \\
\hline 0.0 & 3.2409 & 99.6129 \\
\hline 0.1 & 6.1827 & 98.9037 \\
\hline 0.2 & 10.2254 & 97.5296 \\
\hline 0.3 & 15.2366 & 95.2895 \\
\hline 0.4 & 20.9936 & 92.0781 \\
\hline 0.5 & 27.2380 & 87.9039 \\
\hline 0.6 & 33.7167 & 82.8759 \\
\hline 0.7 & 40.2080 & 77.1743 \\
\hline 0.8 & 46.5327 & 71.0149 \\
\hline 0.9 & 52.5574 & 64.6190 \\
\hline 1.0 & 58.1907 & 58.1907 \\
\hline Lower possibilistic mean & 40.062723 & \\
\hline Upper possibilistic mean & 75.577029 & \\
\hline Crisp possibilistic mean & 57.819876 & \\
\hline Possibilistic standard deviation & 124.500231 & \\
\hline $\begin{array}{l}\text { Possibilistic Coefficient of variance } \\
(\%)\end{array}$ & 215.32 & \\
\hline
\end{tabular}

Table 3. Crisp possibistic mean and Possibilistic variance of solution concentration at various locations.

\begin{tabular}{cccc}
\hline $\begin{array}{l}\text { Downstream } \\
\text { distance }\end{array}$ & $\begin{array}{c}\text { Crisp } \\
\text { possibilistic } \\
\text { mean }(\mathrm{mg} / \mathrm{l})\end{array}$ & $\begin{array}{c}\text { Possibilistic } \\
\text { variance }(\mathrm{mg} / \\
1)\end{array}$ & $\begin{array}{c}\text { Possibilistic } \\
\text { variance }(\mathrm{mg} / \\
1)\end{array}$ \\
\hline 100 & 99.998859 & 0.013867 & 0.01 \\
200 & 99.989527 & 0.111118 & 0.11 \\
300 & 99.938494 & 0.565169 & 0.57 \\
400 & 99.723464 & 2.174219 & 2.18 \\
500 & 98.989751 & 6.713763 & 6.78 \\
600 & 96.914589 & 17.143837 & 17.69 \\
700 & 92.020764 & 36.805762 & 40.0 \\
800 & 82.192712 & 68.865657 & 83.79 \\
900 & 65.776956 & 110.105349 & 167.39 \\
1000 & 45.477148 & 138.74751 & 305.09 \\
1100 & 26.884366 & 135.321683 & 503.35 \\
1200 & 13.798165 & 101.169527 & 733.21 \\
1300 & 6.2808630 & 67.547448 & 1075.45 \\
1400 & 2.5080500 & 39.100678 & 1559.01 \\
1500 & 0.8763470 & 19.199923 & 2190.9 \\
\hline
\end{tabular}

coefficient of variation increases with increase in downstream distance.

In the second set, possibilistic solute concentration is evaluated at a distance of $1220 \mathrm{~m}$ at different times ranging from 100 days to 1000 days. Time dependent solute 


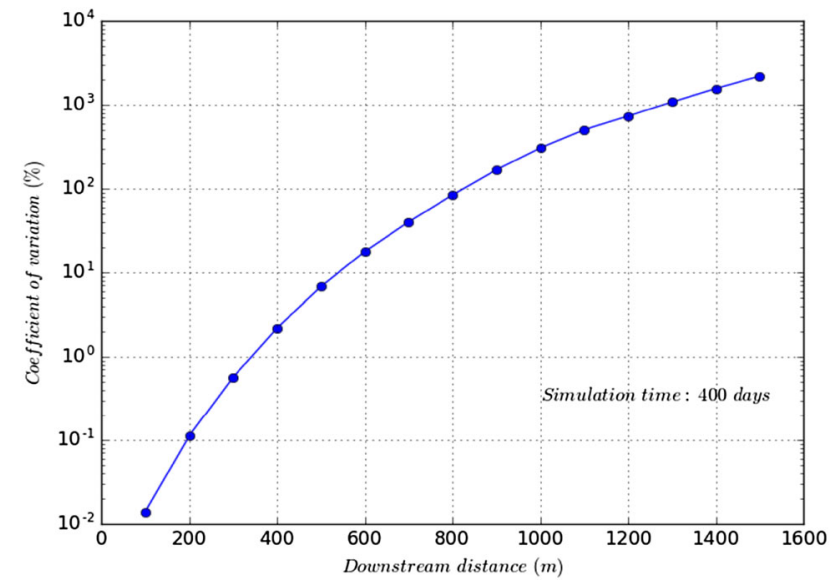

Figure 4. Coefficient of variation at various downstream distances.

concentration band including lower, upper and most probable values at $\mathrm{x}=1220 \mathrm{~m}$ and $\alpha-c u t=0.5$ is shown in figure 5 . The possibility distribution of solute concentration at particular downstream distance of $1220 \mathrm{~m}$ at three different times, $\mathrm{t}=300$ days, 400 days, and 500 days are evaluated and are shown in figure 6.

Values of possibilistic parameters at various simulation times are shown in table 4 . The temporal variation of the Possibilistic coefficient of variation of solute concentration is as shown in figure 7. It can be observed that possibilistic coefficient of variation decreases with increase in observation time.

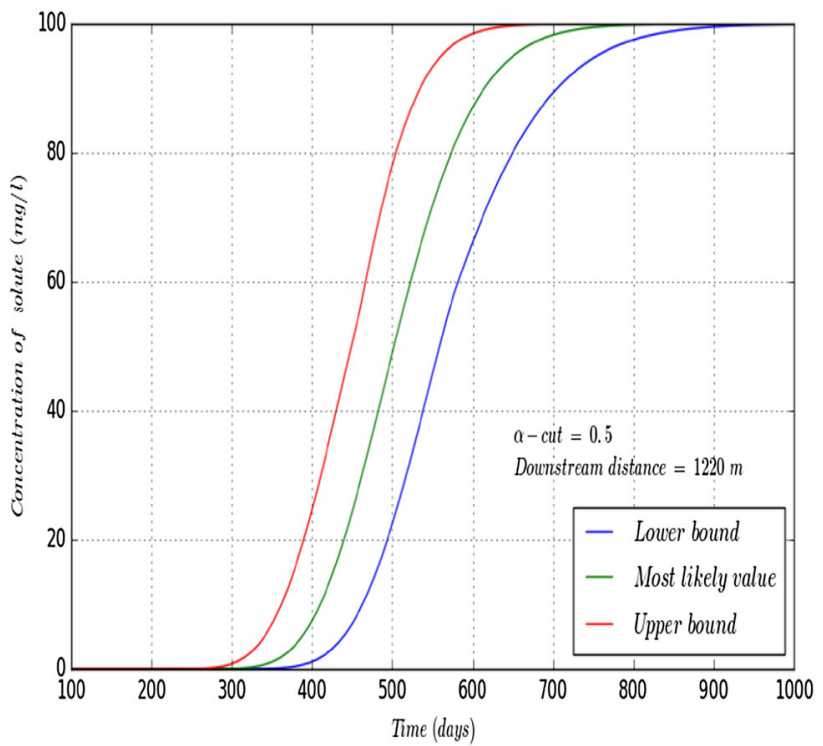

Figure 5. Lower, upper bounds and most probable values of solute at $1220 \mathrm{~m}$.

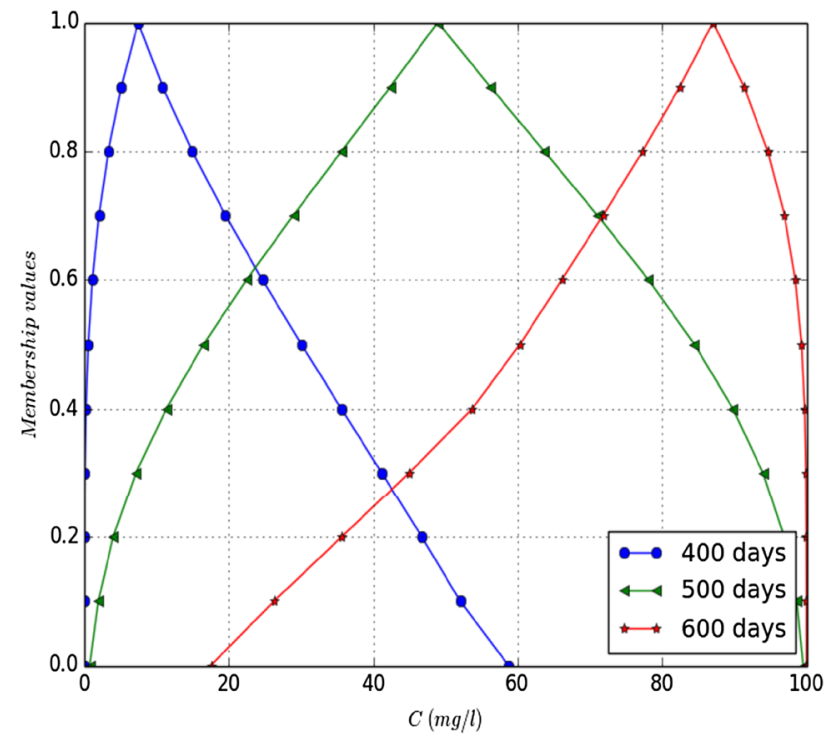

Figure 6. Possibility distribution of solute concentration at times: 300 days, 400 days and 500 days at downstream distance, $\mathrm{x}=1220 \mathrm{~m}$.

Table 4. Temporal variation of crisp possibilistic mean, possibilistic standard deviation and possibilistic coefficient of variation at downstream distance, $\mathrm{x}=1220 \mathrm{~m}$.

\begin{tabular}{cccc}
\hline $\begin{array}{l}\text { Time in } \\
\text { days }\end{array}$ & $\begin{array}{c}\text { Crisp } \\
\text { Possibilistic } \\
\text { mean }\end{array}$ & $\begin{array}{c}\text { Possibilistic } \\
\text { variance }\end{array}$ & $\begin{array}{c}\text { Possibilistic } \\
\text { coefficient of } \\
\text { variance }\end{array}$ \\
\hline 100 & 0.0000 & 0.0000 & 63176.64 \\
200 & 0.0001 & 0.0097 & 8170.33 \\
300 & 0.4533 & 10.5931 & 2336.88 \\
400 & 11.913 & 93.5436 & 785.22 \\
500 & 49.8275 & 142.8909 & 286.77 \\
600 & 82.6902 & 74.6579 & 90.29 \\
700 & 95.0636 & 28.8875 & $30.40 \mathrm{~s}$ \\
800 & 98.6422 & 10.3813 & 10.52 \\
900 & 99.6361 & 3.4562 & 3.47 \\
1000 & 99.9046 & 1.0852 & 1.09 \\
\hline
\end{tabular}

\section{Conclusions}

Membership functions of solute concentration at different spatio-temporal locations are calculated for imprecise solute transport model parameters such as ground water velocity and dispersion coefficient. These membership functions are treated as possibility distributions of solute concentration. Various possibilistic statistical parameters such as possibilistic mean, possibilistic standard deviation and higher order possibilistic moments of solute concentration are derived from the estimated possibility distributions of solute concentration.

Possibilistic standard deviation is expressed as an epistemic uncertainty of the solute transport model. This 


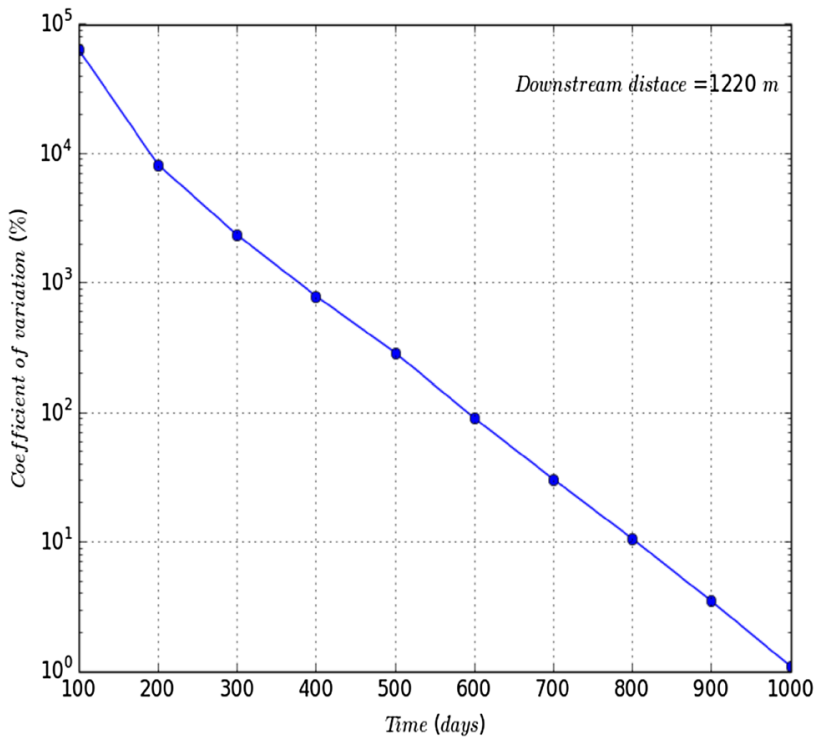

Figure 7. Coefficient of variation of solute concentration at various time at downstream distance, $x=1220 \mathrm{~m}$.

approach eliminates the necessity of expressing uncertainty of outcome of the model in terms of alpha cut. Overall the outcome of this research work explores the application of possibilistic statistics to quantify epistemic uncertainty of solute transport model.

\section{References}

[1] Helton J C 1993 Uncertainty and sensitivity analysis techniques for use in performance assessment for radioactive waste disposal. Reliab. Eng. Syst. Saf. 42: 327-367

[2] Helton J C 1997 Uncertainty and sensitivity analysis in the presence of stochastic and subjective uncertainty. J. Stat. Comput. Simul. 57: 3-76

[3] Ferson S and Lev R G 1996 Different methods are needed to propagate ignorance and variability. Reliab. Eng. Syst. Saf. 54: $133-144$
[4] Datta D 2014 Mathematics of probabilistic uncertainty modeling. In: Mathematics of Uncertainty Modeling in the Analysis of Engineering and Science Problems. Chakraverty S (ed) Hershey PA, IGI Global, pp. 173-204

[5] Zadeh L A 1965 Fuzzy sets. Inf. Control 8: 338-353

[6] Dou W, Woldt W, Bogardi I and Dahab M 1997 Numerical solute transport simulation using fuzzy sets approach. J. Contam. Hydrol. 27: 107-126

[7] Datta D and Pal T K 2017 Development of fuzzy differential quadrature numerical method and its application for uncertainty quantification of solute transport model. Life Cycle Reliab. Saf. Eng. 6: 249-256

[8] Pal T K and Datta D 2017 Parametric uncertainty analysis of solute transport process using fuzzy lattice Boltzmann scheme. Life Cycle Reliab. Saf. Eng. 6: 249-256

[9] Zadeh L A 1978 Fuzzy sets as a basis for a theory of Possibility. Fuzzy Sets Syst. 1: 3-28

[10] Dubois D and Prade H 1988 Possibility theory. New York: Plenum Press

[11] Dubois D and Prade H 1987 The mean value of a fuzzy number. Fuzzy Sets Syst. 24: 279-300

[12] Carlsson C and Fullér R 2001 On possibilistic mean value and variance of fuzzy numbers. Fuzzy Sets Syst. 122: $315-326$

[13] Dubois D and Prade H 1988 Fuzzy sets and systems: theory and application. New York: Academic Press

[14] Klir G J and Yuan B 1995 Fuzzy sets and fuzzy logic: theory and applications. New Jersey: Prentice Hall

[15] Dubois D and Prade H 1988 Possibility theory: an approach to computerized processing of uncertainty. New York: Plenum Press

[16] Bobba A G, Singh V P and Bengtsson L G 1995 Application of uncertainty analysis to groundwater pollution modeling. Environ. Geol. 26: 89-96

[17] Ozbek M M, Metin M, and George F P 2006 Non-probabilistic uncertainty in subsurface hydrology and its applications: an overview. Water Air Soil Pollut Focus 6: $35-46$

[18] Datta D 2010 Uncertainty modeling of pollutant transport in atmosphere and aquatic route using soft computing. AIP Conf. Proc. 1298: 37-42

[19] Dong W and Shah H C 1987 Vertex method for computing functions of fuzzy variables. Fuzzy Sets Syst. 24: 65-78 